\title{
Glycine and succinic acid are effective indicators of the suppression of epithelial-mesenchymal transition by fucoxanthinol in colorectal cancer stem-like cells
}

\author{
MASARU TERASAKI ${ }^{1,2}$, MASATOSHI MIMA $^{1}$, SATOKI KUDOH $^{1}{ }^{2}$ TETSUYA ENDO $^{1}$, HAYATO MAEDA $^{3}$, \\ JUNICHI HAMADA ${ }^{2,4}$, KAZUMI OSADA ${ }^{5}$, KAZUO MIYASHITA ${ }^{6}$ and MICHIHIRO MUTOH ${ }^{7}$
}

\author{
${ }^{1}$ School of Pharmaceutical Sciences and ${ }^{2}$ Cancer Prevention Laboratories, Health Sciences University of Hokkaido, \\ Ishikari-Tobetsu, Hokkaido 061-0293; ${ }^{3}$ Faculty of Agriculture and Life Science, Hirosaki University, Hirosaki, \\ Aomori 036-8561; ${ }^{4}$ School of Nursing and Social Services, and ${ }^{5}$ School of Dentistry, Health Sciences University of Hokkaido, \\ Ishikari-Tobetsu, Hokkaido 061-0293; ${ }^{6}$ Laboratory of Biofunctional Material Chemistry, Division of Marine Bioscience, \\ Graduate School of Fisheries Sciences, Hokkaido University, Hakodate, Hokkaido 041-8611; ${ }^{7}$ Epidemiology and \\ Preventions Group, Center for Public Health Sciences, National Cancer Center, Tokyo 104-0045, Japan
}

Received November 21, 2017; Accepted March 30, 2018

DOI: $10.3892 / o r .2018 .6398$

\begin{abstract}
Fucoxanthinol $(\mathrm{FxOH})$ is a strong anticancer metabolite of fucoxanthin that accumulates in abundance in edible brown algae and promises human health benefits. FxOH has been shown to suppress tumorigenicity and sphere formation in human colorectal cancer stem cell (CCSC)-like spheroids (colonospheres, Csps). In the present study, we aimed to clarify the inhibitory activity of FxOH on epithelialmesenchymal transition (EMT), which is essential for cancer recurrence and distant metastasis, and to identify intracellular low-molecular-weight metabolites that may be useful for evaluating the cellular effects of $\mathrm{FxOH}$ on CCSCs. FxOH significantly suppressed sphere-forming activity, migration and invasion in a dose-dependent manner. In addition, treatment with $50 \mu \mathrm{mol} / 1 \mathrm{FxOH}$ suppressed $\mathrm{N}$-cadherin and vimentin expression and the activation of integrin signaling linked to EMT suppression by western blot analysis. MAPK signaling and STAT signaling related to cell growth and apoptosis in
\end{abstract}

Correspondence to: Dr Masaru Terasaki, School of Pharmaceutical Sciences, Health Sciences University of Hokkaido, 1757 Kanazawa, Ishikari-Tobetsu, Hokkaido 061-0293, Japan

E-mail: terasaki@hoku-iryo-u.ac.jp

Abbreviations: CCSCs, colorectal cancer stem cells; CD44s, CD44 standard form; CD44v, CD44 variant forms; Csps, colonospheres; DEN, diethylnitrosamine; DMEM, Dulbecco's modified Eagle's medium; DMSO, dimethyl sulfoxide; DW, distilled water; EMT, epithelial-mesenchymal transition; FBS, fetal bovine serum; $\mathrm{FxOH}$, fucoxanthinol; Fx, fucoxanthin; 2-IPMA, 2-isopropylmalic acid; MSTFA, $N$-methyl- $N$ (trimethylsilyl)-trifluoroacetate; PCs, parental cells; PPAR, peroxisome proliferator-activated receptor; SCM, stem cell medium

Key words: fucoxanthinol, colonosphere, colorectal cancer stem cells, epithelial-mesenchymal transition, metabolite
Csps derived from human CRC HT-29 and HCT116 cells were also altered. According to our metabolite profiling by GC-MS analysis, reduced glycine and succinic acid levels were correlated with EMT suppression and apoptosis induction in Csps. Our data indicate that simple amino acids such as glycine and succinic acid may be good prognostic indicators of physiological changes to CCSCs induced by $\mathrm{FxOH}$ treatment.

\section{Introduction}

Fucoxanthin (Fx) is a non-provitamin A of high polar xanthophyll that has an unusual allenic bond, an epoxide group and a conjugated carbonyl group in a polyene chain. Fx occurs dominantly in marine brown algae and diatoms and is responsible for photosynthesis and photoprotection. Undaria pinnatifida (wakame), Hizikia fusiforme (hiziki) and Sargassum horneri (akamoku) are particularly excellent sources of Fx among Japanese algal foods $(1,2)$. It has been demonstrated that Fx is extremely safe in terms of toxicity, showing no adverse effects in animal experiments $(3,4)$. Several researchers have conclusively reported the anticancer (5-7), anti-inflammatory (8), anti-diabetic (9) and anti-obesity effects of Fx in animals and humans $(10,11)$. Moreover, Fx possesses strong potential for cell growth inhibition and the induction of apoptosis in human neuroblastoma, gastric cancer, hepatoma, colorectal cancer (CRC) and promyelocytic leukemia cells (12-16). Fx is metabolically converted to fucoxanthinol (FxOH) (Fig. 1) and amarouciaxanthin A (Amx A) in the mouse intestine and liver (17). After the oral administration of wakame or Fx concentrate in humans, higher levels of $\mathrm{FxOH}$ and lower levels of $c i s-\mathrm{FxOH}$ have been detected in human plasma $(18,19)$. Thus, $\mathrm{FxOH}$ is an important indicator of Fx function and may be a promising candidate for human cancer chemoprevention. FxOH significantly attenuated the proliferation of cancer cells derived and cultured from human CRC tissue (20). However, despite the strong anticancer effects of $\mathrm{FxOH}$, its underlying mechanisms are not well known. 
CRC is the third most common cause of cancer-related death worldwide, and therefore it is urgent to reduce CRC prevalence (21). Although non- or less polar carotenoids such as $\beta$-carotene and lutein exhibit cancer preventive effects, as shown in many epidemiological studies, their utility has 'insufficient evidence'. In the case of Fx or brown algae, prospective clinical trials, cohorts or follow-back studies for cancer prevention have not been attempted.

CRC stem cells (CCSCs) occupy only a small subset of CRC tissue, but they are thought to play a central role in cancer development. Self-renewal, differentiation, sphere formation, and tumorigenicity in immunodeficient animals have been characterized for CCSCs $(22,23)$. CCSCs often acquire an epithelial-mesenchymal transition (EMT) phenotype accompanied by the activation of related proteins, and EMT not only promotes their migration and invasion, but is also believed to be a leading cause of CRC recurrence and distant metastasis (24). Therefore, attenuation of the EMT phenotype of CCSCs may represent a promising approach for cancer prevention, cancer recurrence/metastasis prevention and survival rate elongation. It is well known that spheroids formed from CRC cells, called colonospheres (Csps), are considered a representative CCSC model phenotype since they contain a high abundance of CCSCs and possess sphere reconstruction and tumorigenic capacities $(22,23,25)$. We recently revealed that $\mathrm{FxOH}$ strongly induces the apoptosis of HT-29 Csps and attenuates tumorigenicity in a xenograft mouse model (26). However, little information regarding the EMT-suppressing effects of FxOH on CCSCs or Csps is available to date. Moreover, there are no studies reports regarding the anti-metastatic effects of $\mathrm{FxOH}$ in in vivo setting. Thus, we aimed to clarify the inhibitory activity of FxOH on EMT in the present study.

Intracellular low-molecular-weight metabolites that are essential for regulating energy systems such as glycolysis and the TCA cycle are suggested to be prognostic indicators representing cellular genomic and proteomic alterations after encounters with various endogenous and exogenous stimuli. Comprehensive metabolite analyses have revealed many marker metabolite candidates in serum, plasma, urine and cancer tissue in CRC patients and an animal model (27-29). Therefore, intracellular low-molecular-weight metabolites likely represent a convenient approach to promptly diagnose the cellular conditions of CCSCs with complicated genetic and protein backgrounds. However, the marker metabolites representing the EMT phenotype in CCSCs remain elusive.

In the present study, we investigated the EMT-suppressive effects of $\mathrm{FxOH}$ on Csps formed from human CRC HT-29 and HCT116 cells. The molecules through which FxOH exerted EMT suppression were investigated. In addition, we examined the alterations exerted by $\mathrm{FxOH}$ on the metabolite profiles of Csps and identified marker metabolites with EMT potential in Csps.

\section{Materials and methods}

Chemicals and cell culture. All-trans-FxOH (purity, $\geq 98 \%$ ) was provided by Dr Hayato Maeda (Hirosaki University, Japan) (Fig. 1). EGF, bFGF and DMEM/F12 medium were purchased from Wako Pure Chemicals (Osaka, Japan). B27 was obtained from Miltenyi Biotec, Inc. (Auburn, CA, USA). HT-29 and HCT116 human CRC cells were purchased from the American Type Culture Collection (ATCC; Manassas, VA, USA). These cells were cultured in Dulbecco's modified Eagle's medium (DMEM) supplemented with $10 \%$ heat-inactivated fetal bovine serum (FBS), $4 \mathrm{mM}$ L-glutamine, 40,000 U/1 penicillin and $40 \mathrm{mg} / \mathrm{l}$ streptomycin. All other chemicals and solvents were of analytical grade.

Colonosphere formation. HT-29 and HCT116 parental cells (PCs) were trypsinized from culture plates, washed twice with PBS, suspended in stem cell medium (SCM) composed of DMEM/F12 medium, $20 \mathrm{ng} / \mathrm{ml} \mathrm{EGF,} 10 \mathrm{ng} / \mathrm{ml} \mathrm{bFGF,} \mathrm{0.2 \%} \mathrm{B27}$ and an antibiotic-anti-mycotic agent, plated at a density of $3 \times 10^{4}$ cells $/ \mathrm{ml} \mathrm{SCM}$ in $10-\mathrm{cm}$ dishes or 24 -well ultra-low attachment plates (Corning Inc., Corning, NY, USA) and incubated for 2 days at $37^{\circ} \mathrm{C}$ in a humidified atmosphere containing $5 \% \mathrm{CO}_{2}$. All experiments utilizing colonospheres (Csps) described below were performed using Csps grown for 2 days.

Analysis of the suppression of colonosphere formation. Csps derived from HT-29 and HCT116 PCs were formed in a 24-well ultra-low attachment plate for 2 days. After the Csps formed, a total of 2-10 mM FxOH reconstituted in dimethyl sulfoxide (DMSO) was applied to the cell medium at a final concentration of $10-50 \mu \mathrm{M}(0.5 \mathrm{v} / \mathrm{v} \%)$, or vehicle alone (DMSO) was applied. The cells were harvested and trypsinized after incubation for $24 \mathrm{~h}$. Viable cells in Csps were counted using a trypan blue exclusion method. The Csps treated with FxOH were treated with ribonuclease A, stained with propidium iodide (PI) and subjected to flow cytometry. The percentage of apoptotic cells (sub-G1, hypodiploid cells) was estimated by a FACSaria-III flow cytometer (BD Biosciences, San Jose, CA, USA).

Western blot analysis. pAkt $\left(\operatorname{Ser}^{473}\right)$ (cat. no. 4060), $\beta$-catenin (cat. no. 9582), p $\beta$-catenin $\left(\operatorname{Ser}^{31} / 37 / \mathrm{Thr}^{42}\right)$ (cat. no. 9561), cyclin D1 (cat. no. 2922) and PPAR $\gamma$ (cat. no. 2435) antibodies and phospho-ERK1/2 pathway (cat. no. 9911) and phospho-Stat antibody sampler (cat. no. 9914) kits were purchased from Cell Signaling Technology, Inc. (Danvers, MA, USA). $\beta$-actin (cat. no. GTX109639), E-cadherin (cat. no. GTX100443), N-cadherin (cat. no. GTX127345), caspase-3 (cat. no. GTX110543), pFAK ( Tyr $^{397}$ ) (cat.no. GTX24803), LGR5 (cat. no. GTX129862) and vimentin (cat. no. GTX132610) antibodies were obtained from GeneTex (Irvine, CA, USA). The paxillin $\left(\mathrm{Tyr}^{31}\right.$ ) antibody (MAB61641) was obtained from R\&D Systems (Minneapolis, MN, USA). CD44 (cat. no. MS-668-P0), MMP-9 (cat. no. MS-817-P0) and p53 (cat. no. MS-105-P0) antibodies were obtained from Thermo Fisher Scientific, Inc. (Waltham, MA, USA). EpCAM (cat. no. 11-581-C025) and integrin $\beta 1$ (cat. no. 11-219C100) antibodies were obtained from Exbio (Prague, Czech Republic). Epithelial type cells obtained immediately before preparing Csps were used as the parental cells (PCs) of the Csps. Csps derived from HT-29 and HCT116 PCs formed in 10 -cm ultra-low attachment plates for 2 days and were then treated with $50 \mu \mathrm{M}$ FxOH and vehicle (DMSO) for 4-24 h. The cells were harvested, washed twice with phosphate-buffered saline (PBS) and then lysed in a lysis buffer to obtain wholecell lysates. The protein concentrations were photometrically measured using the Bradford assay (Bio-Rad, Hercules, CA, 


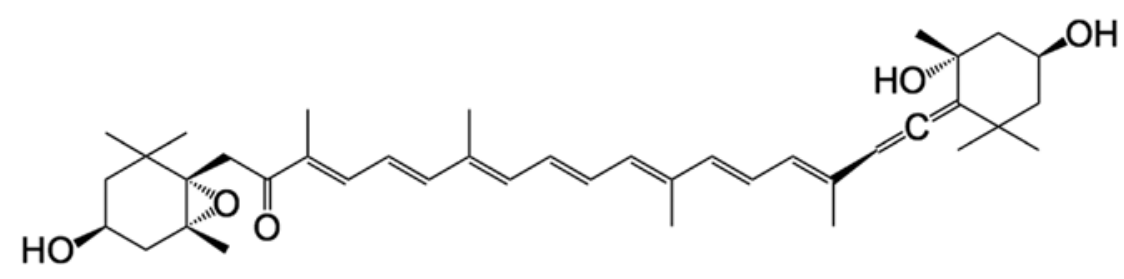

Figure 1. Chemical structure of fucoxanthinol (FxOH). Molecular weight, 616.87.

USA). Fifty micrograms of whole-cell proteins were separated on SDS-polyacrylamide minigels. The gels were then electroblotted onto polyvinylidene fluoride (PVDF) membranes. The PVDF membranes were incubated in $1 \%$ BSA blocking buffer at room temperature and probed with each of the primary antibodies (1:1,000 dilution) in blocking buffer overnight at $4^{\circ} \mathrm{C}$ following the manufacturer's instructions. The membranes were washed and incubated with HRP-conjugated anti-mouse or anti-rabbit secondary antibodies. The membranes were again washed and subsequently subjected to chemiluminescence reagents. The stripping process to avoid the detection of previous bands may induce unclear blot when we use a new antibody on the same membrane. Thus, we repeated western blotting, loading the same amount of sample, to obtain the new membrane for several times.

Migration and invasion analyses. Migration and invasion assays were performed using a 24-well Transwell chamber with an $8-\mu \mathrm{m}$ pore size and a 24 -well Matrigel invasion chamber (pore size, $8 \mu \mathrm{m}$ ) (Corning Costar, Cambridge, MA, USA). Csps derived from HT-29 and HCT116 PCs formed in 10-cm ultra-low attachment plates for the assays, were trypsinized and were washed twice with PBS. Then, $3 \times 10^{4}$ suspended cells were seeded in $500 \mu 1$ of SCM in a $15-\mathrm{ml}$ centrifuge tube and treated with $\mathrm{FxOH}(20$ and $50 \mu \mathrm{M})$ or vehicle (DMSO). One hundred microliters of the cell suspension containing FxOH was applied to the upper compartment of each chamber. DMEM containing 10\% FBS was loaded into the lower compartment in both chambers. The migration and invasion chambers were then incubated for 6 and $24 \mathrm{~h}$, respectively, at $37^{\circ} \mathrm{C}$. Cells that migrated or invaded to the underside of the upper compartment were fixed with formalin and stained with Giemsa solution/(1:00 dilution). Migrated or invaded cells were visualized at $\mathrm{x} 40$ magnification and counted as the numbers of migrated or invaded cells/field in three random fields.

GC-MS analysis. 2-Isopropylmalic acid (2-IPMA), methoxyamine hydrochloride and $N$-methyl- $N($ trimethylsilyl)trifluoroacetate (MSTFA) were obtained from Sigma-Aldrich (Merck KGaA, Darmstadt, Germany), MP Biomedicals (Solon, $\mathrm{OH}, \mathrm{USA}$ ) and GL Sciences (Tokyo, Japan), respectively. Csps treated with $\mathrm{FxOH}$ were harvested from culture plates, trypsinized, and washed twice with PBS. The pelleted cells were re-suspended in $50 \mu 1$ of cold PBS, to which $2 \mu 1$ of $0.1 \mathrm{mg} / \mathrm{ml}$ 2-IPMA was added as an internal standard, and then the suspensions were disrupted by sonication for $5 \mathrm{sec}$ on ice. Total protein contents were determined using the Bradford method with $1 \mu 1$ of each suspension. Metabolites were extracted with $250 \mu \mathrm{l}$ of $\mathrm{CH}_{3} \mathrm{OH} / \mathrm{CHCl}_{3} / \mathrm{DW}(2.5: 1: 1, \mathrm{v} / \mathrm{v} / \mathrm{v})$, centrifuged at $16,000 \mathrm{x} \mathrm{g}$ for $5 \mathrm{~min}$ and the upper phase was washed with $200 \mu \mathrm{l}$ of DW.
The extracts obtained were evaporated to dryness. The residues were oxymated with $30 \mu 1$ of $20 \mathrm{mg} / \mathrm{ml}$ methoxyamine hydrochloride in dry pyridine at $30^{\circ} \mathrm{C}$ for $90 \mathrm{~min}$, followed by the application of $15 \mu \mathrm{l}$ of MSTFA at $37^{\circ} \mathrm{C}$ for $30 \mathrm{~min}$. All GC-MS analyses were carried out using a GCMS-QP5000 system (Shimadzu, Kyoto, Japan) equipped with a non-polar capillary column [Rxi-5ms, $30 \mathrm{~m}$ x $0.25 \mathrm{~mm}$ i.d., film thickness, $0.25 \mu \mathrm{m}$; Restek, Co. Ltd., GmbH (Bad Homburg, Germany)] and online analysis software (CLASS 5000). The carrier gas $(\mathrm{He})$ flow rate was at $0.5 \mathrm{ml} / \mathrm{min}(15.7 \mathrm{kPa})$, and injections were $1 \mu \mathrm{l}$ in split-ratio mode (split ratio, 33\%). The column temperature was initially $80^{\circ} \mathrm{C}$ for $2 \mathrm{~min}$, increased to $330^{\circ} \mathrm{C}$ at $4^{\circ} \mathrm{C} / \mathrm{min}$ and then maintained at $330^{\circ} \mathrm{C}$ for $8 \mathrm{~min}$. The interface and source temperatures were 250 and $230^{\circ} \mathrm{C}$, respectively. Identification was confirmed by comparing the spectra of single components with those stored in the acquisition system library. All metabolite contents were expressed as pmol metabolite $/ \mu \mathrm{g}$ of total protein content.

Statistical analysis. All experiments were performed at least twice and are presented as representative data. Significant differences for multiple comparisons were determined by one-way ANOVA followed by Tukey-Kramer post hoc test. Differences were considered statistically significant at $\mathrm{P}<0.05$ as indicated with the relevant symbols in the figures.

\section{Results}

Stemness and metabolite characteristics of colonospheres. Among the three CCSC surface markers (CD44, EpCAM and LGR5), CD44 variant forms (CD44v) and EpCAM were overexpressed in both HT-29 and HCT116 Csps compared with the PCs (Fig. 2). CD44 standard form (CD44s) and LGR5 were strongly increased in HT-29 Csps, while LGR5 was weakly increased in HCT116 Csps. Among the three key proteins representing the EMT phenotype (E-cadherin, N-cadherin and vimentin), the expression of E-cadherin and vimentin was elevated in both Csps compared with the expression in the PCs. N-cadherin expression did not discriminate between Csps and PCs for both cell types.

In the next experiment, metabolite profiles were constructed using GC-MS (Fig. 3). The quantitative data obtained for the Csps and PCs derived from both cell types for all 20 metabolites analyzed are presented in Table I. Four amino acids, specifically glycine, serine, threonine and glutamic acid, as well as succinic acid, a TCA cycle metabolite, were significantly increased in the HCT116 Csps compared with the PCs. Although no significant changes were observed between HT-29 Csps and PCs, there was a tendency toward a changing pattern for these five metabolites similar to that of HCT116 cells. 

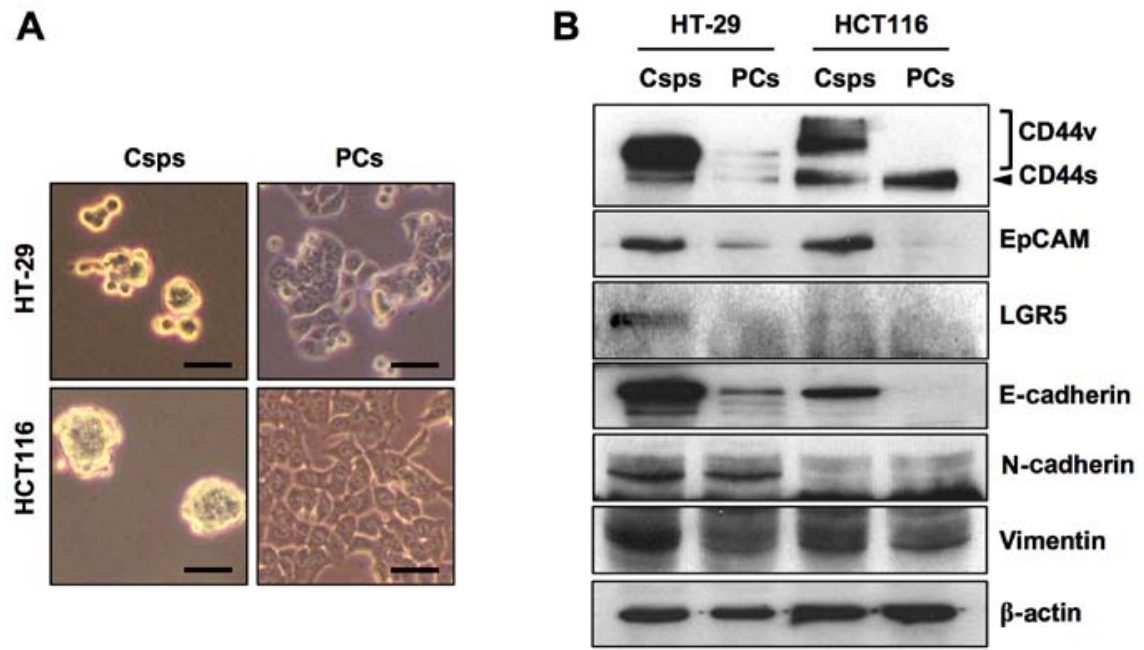

Figure 2. Marker proteins related to colorectal cancer stem cells and the epithelial-mesenchymal transition of colonospheres (Csps) formed from HT-29 and HCT116 parental cells (PCs). Csps were prepared with stem cell medium for 2 days. (A) Images of PCs and Csps derived from HT-29 and HCT116 cells by phase-contrast microscopy. Scale bar, $100 \mu \mathrm{m}$. (B) PCs and Csps were collected, and their protein levels were determined by western blotting.

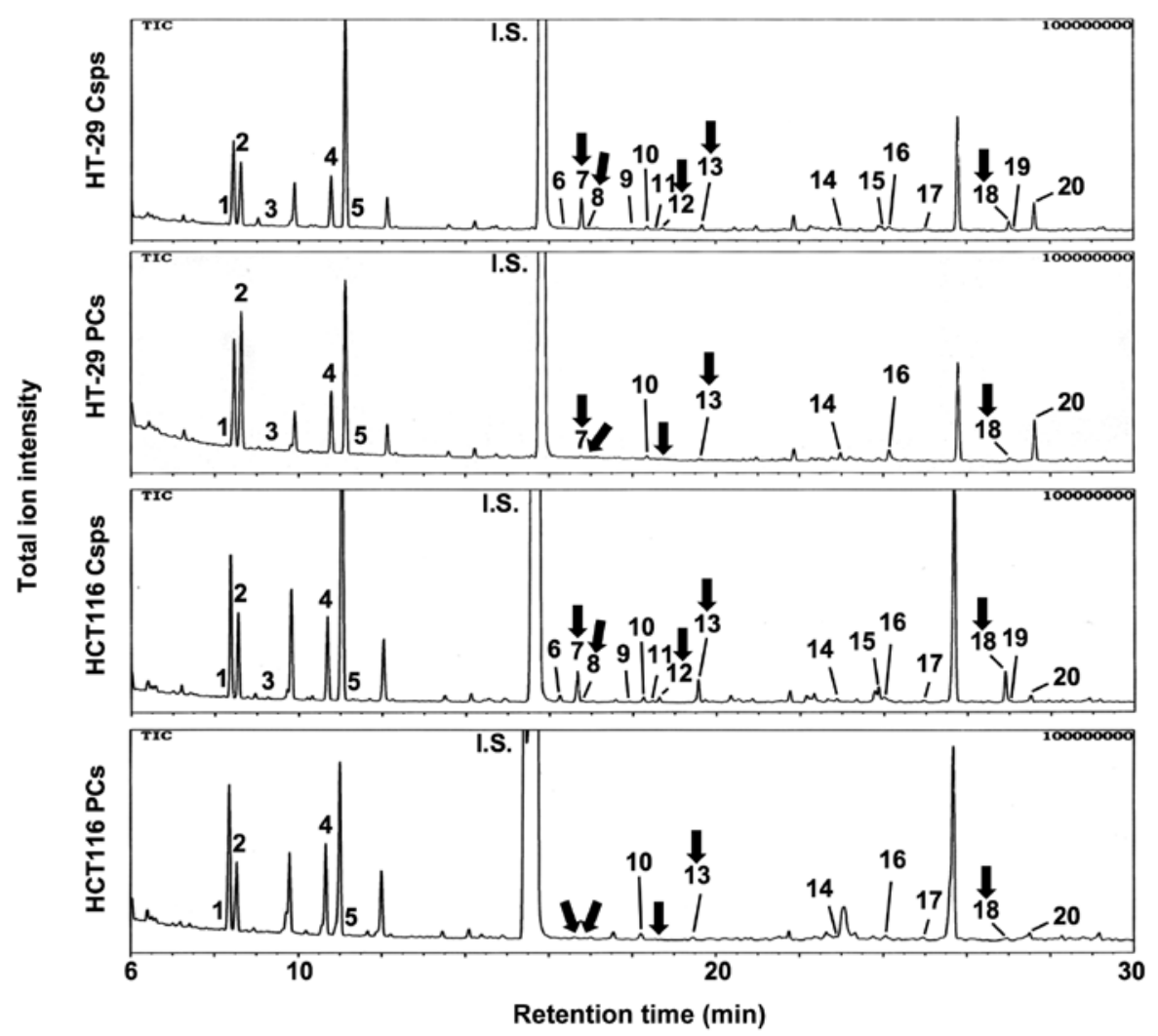

Figure 3. GC-MS total ion chromatograms of metabolites in colonospheres (Csps) formed from HT-29 and HCT116 parental cells (PCs). Csps and PCs derived from HT-29 and HCT116 cells were collected, and their metabolites were analyzed by GC-MS. Peak nos. 7, 8, 12, 13 and 18 indicate glycine, serine, threonine, glutamic acid and succinic acid, respectively (black arrows). Information on cellular metabolites corresponding to each peak number is shown in Table I. GC-MS conditions are documented in Materials and methods.

Overall, metabolites were weakly increased in Csps compared with the PCs, but no significant change was observed for other metabolites from Csps or PCs derived from both cell lines.

Antiproliferative effects of $\mathrm{FxOH}$ in colonospheres. Treatment with 10,20 and $50 \mu \mathrm{M} \mathrm{FxOH}$ inhibited the growth of Csps from the HT-29 and HCT116 cells in a dose-dependent manner (Fig. 4A and B). Sphere formation was as follows for Csps from HT-20 and HCT116 cells: $10 \mu \mathrm{M}$ FxOH, $86.7 \pm 7.1$ and $116.3 \pm 10.4 \%$, respectively; $20 \mu \mathrm{M}, 77.0 \pm 7.0$ and $95.0 \pm 9.4 \%$, respectively; and $50 \mu \mathrm{M}, 57.7 \pm 11.0$ and $52.1 \pm 5.4 \%$, respectively. Vehicle (DMSO) alone exerted no effects on cell proliferation. Flow-cytometric analyses exhibited that the percentage of sub-G1 phase cells (apoptosis-induced cells) in the FxOH-treated Csps $(35.4 \pm 0.5 \%)$ was higher than that noted in the control Csps $(5.6 \pm 1.0 \%)$ (Fig. 4C). In addition, $\mathrm{FxOH}$ 
Table I. Metabolite profiles of the colonospheres from HT-29 and HCT116 parental cells.

\begin{tabular}{|c|c|c|c|c|c|}
\hline \multirow[b]{3}{*}{ Peak no. ${ }^{a}$} & \multirow[b]{3}{*}{ Group - compound } & \multicolumn{4}{|c|}{$\mathrm{pmol}$ metabolite $/ \mu \mathrm{g}$ total protein content } \\
\hline & & \multicolumn{2}{|c|}{ HT-29 cells } & \multicolumn{2}{|c|}{ HCT116 cells } \\
\hline & & Csps & PCs & Csps & PCs \\
\hline & Amino acid & & & & \\
\hline 3 & Valine & $2.9 \pm 2.1$ & $0.6 \pm 0.6$ & $0.1 \pm 0.1$ & $2.7 \pm 2.7$ \\
\hline 5 & Leucine & $1.4 \pm 0.8$ & $1.6 \pm 1.6$ & $1.6 \pm 0.7$ & ND \\
\hline 6 & Proline & $6.6 \pm 2.3$ & ND & ND & ND \\
\hline 7 & Glycine & $19.3 \pm 3.9$ & $6.9 \pm 3.1$ & $16.6 \pm 2.2^{\mathrm{b}}$ & $1.0 \pm 0.5$ \\
\hline 11 & Alanine & ND & ND & $0.6 \pm 0.6$ & ND \\
\hline 12 & Serine & $2.2 \pm 0.5$ & $0.6 \pm 0.6$ & $2.6 \pm 0.2^{\mathrm{b}}$ & ND \\
\hline 13 & Threonine & $6.2 \pm 0.7$ & $2.4 \pm 1.6$ & $10.6 \pm 1.1^{\mathrm{b}}$ & $0.5 \pm 0.5$ \\
\hline 15 & Aspartic acid & $3.8 \pm 0.8$ & $1.8 \pm 1.1$ & $3.7 \pm 3.7$ & ND \\
\hline 18 & Glutamic acid & $9.0 \pm 2.3$ & $2.6 \pm 1.1$ & $13.2 \pm 1.4^{\mathrm{b}}$ & $0.9 \pm 0.5$ \\
\hline \multirow[t]{2}{*}{19} & Phenylalanine & $0.5 \pm 0.4$ & $0.7 \pm 0.4$ & $0.1 \pm 0.1$ & ND \\
\hline & Dicarboxylic acid (TCA cycle) & & & & \\
\hline 8 & Succinic acid & $2.8 \pm 1.8$ & $0.5 \pm 0.5$ & $0.9 \pm 0.3^{\mathrm{b}}$ & ND \\
\hline 9 & Fumaric acid & $0.5 \pm 0.5$ & ND & $0.1 \pm 0.1$ & ND \\
\hline \multirow[t]{2}{*}{14} & Malic acid & $3.2 \pm 1.2$ & $5.6 \pm 1.1$ & $1.5 \pm 1.5$ & $0.5 \pm 0.5$ \\
\hline & Carboxylic acid & & & & \\
\hline 1 & Pyruvic acid & $1.4 \pm 0.8$ & $1.1 \pm 1.1$ & $2.0 \pm 0.3$ & $1.7 \pm 0.4$ \\
\hline 2 & Propionic acid & $74.2 \pm 10.0$ & $97.1 \pm 23.9$ & $54.5 \pm 6.2$ & $59.4 \pm 19.4$ \\
\hline 4 & Butyric acid & $34.3 \pm 5.1$ & $41.5 \pm 6.9$ & $63.7 \pm 10.3$ & $51.6 \pm 4.6$ \\
\hline 10 & Pelargonic acid & $3.8 \pm 0.8$ & $3.1 \pm 0.5$ & $4.9 \pm 0.3$ & $3.2 \pm 0.8$ \\
\hline 16 & $\gamma$-aminobutyric acid & $5.6 \pm 2.0$ & $9.1 \pm 1.1$ & $6.7 \pm 1.7$ & $2.3 \pm 0.6$ \\
\hline 17 & 2,3,4-trihydroxybutyric acid & ND & ND & $0.9 \pm 0.9$ & $0.8 \pm 0.4$ \\
\hline 20 & Lauric acid & $10.1 \pm 4.5$ & $12.9 \pm 11.4$ & $8.8 \pm 4.0$ & $8.6 \pm 3.4$ \\
\hline
\end{tabular}

All data are expressed as mean $\pm \mathrm{SE}\left(\mathrm{n}=3\right.$ ). ${ }^{\mathrm{a} T h e}$ number of peak shown in Fig. 3 ; ${ }^{\mathrm{b}} \mathrm{P}<0.05$ (one-way ANOVA followed by post hoc Tuker-Kramer test vs. parental cells of each cell type). ND, a metabolite was not detected over signal/noise ratio (3:1) by GC-MS. Csps, colonospheres; PCs, parental cells.

abrogated p53 expression and increased the p17 and p19 active subunits of caspase-3, suggesting that this growth inhibition is linked to apoptosis (Fig. 7).

Suppressive effects of $\mathrm{FxOH}$ on the migration and invasion of colonospheres. Treatment with 20 and $50 \mu \mathrm{M} \mathrm{FxOH}$ inhibited the migration and invasion of both HT-29 and HCT116 Csps in a dose-dependent manner (Fig. 5). Migration activities were as follows for Csps from HT-29 and HCT116 cells: $20 \mu \mathrm{M} \mathrm{FxOH,}$ $82.1 \pm 9.3$ and $75.7 \pm 13.2 \%$, respectively; and $50 \mu \mathrm{M}, 15.0 \pm 7.4$ and $16.7 \pm 4.2 \%$, respectively. Invasion activities were as follows for HT-29 and HCT116 Csps: $20 \mu \mathrm{M} \mathrm{FxOH,} \mathrm{52.8 \pm 3.3} \mathrm{and}$ $47.4 \pm 2.7 \%$, respectively; and $50 \mu \mathrm{M}, 13.4 \pm 2.7$ and $7.4 \pm 1.3 \%$, respectively. Vehicle (DMSO) alone exerted no effects on both migration and invasion capacities.

Changes in the metabolite profiles of colonospheres with and without $\mathrm{FxOH}$. Csps derived from both cell types were treated with $50 \mu \mathrm{M}$ FxOH, and a total of 20 metabolites were analyzed using GC-MS. The quantitative data are presented in Table II and Fig. 6. Among them, three amino acids, specifically glycine, threonine and glutamic acid, were significantly decreased in both or either Csps compared with control Csps. Succinic acid, a carboxylic acid involved in the TCA cycle, was significantly decreased in both HT-29 and HCT116 Csps compared with control Csps. Although no significant change was observed in other metabolites, the majority of metabolites were weakly decreased in both HT-29 and HCT116 Csps treated with $\mathrm{FxOH}$ compared with control Csps.

Expression of molecules related to $\mathrm{FxOH}$ treatment. To clarify the proteins involved in the inhibition of EMT, invasion and migration, we performed a western blot assay. FxOH treatment increased E-cadherin at $24 \mathrm{~h}$ and decreased $\mathrm{N}$-cadherin at $24 \mathrm{~h}$ and vimentin at $8 \mathrm{~h}$ in Csps in both cell lines (Fig. 7). FxOH also decreased the activation of integrin, MAPK and Stat signaling by inhibiting phosphorylation of their key proteins in Csps in both cell lines. Regarding integrin signaling, protein levels of Integrin $\beta 1$ and phosphorylation levels of paxillin and Akt are clearly reduced at $24 \mathrm{~h}$. The phosphorylation levels of pFAK and protein levels of PPAR $\gamma$ were reduced in a time-dependent manner. Regarding MAPK 
A
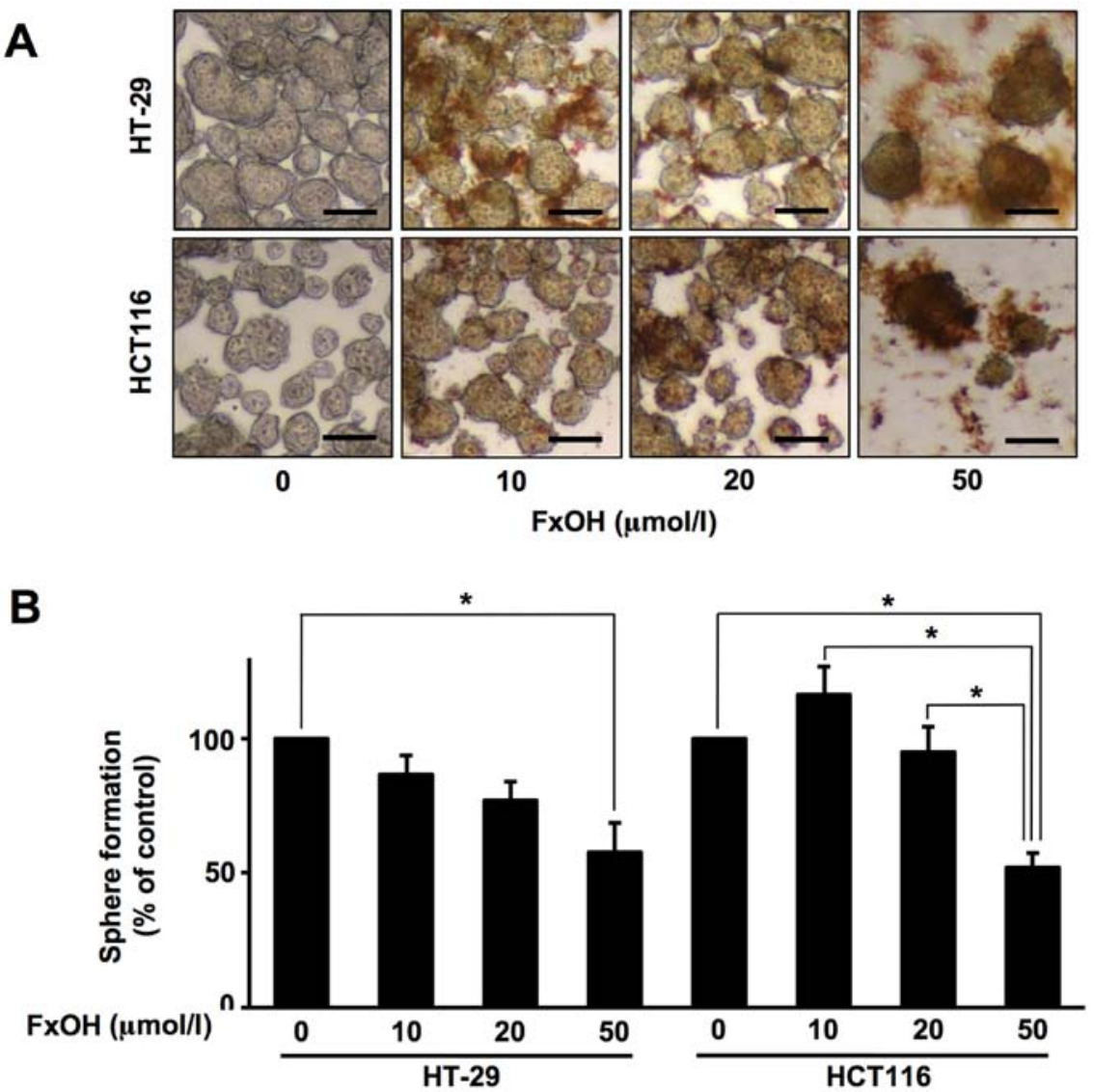

C
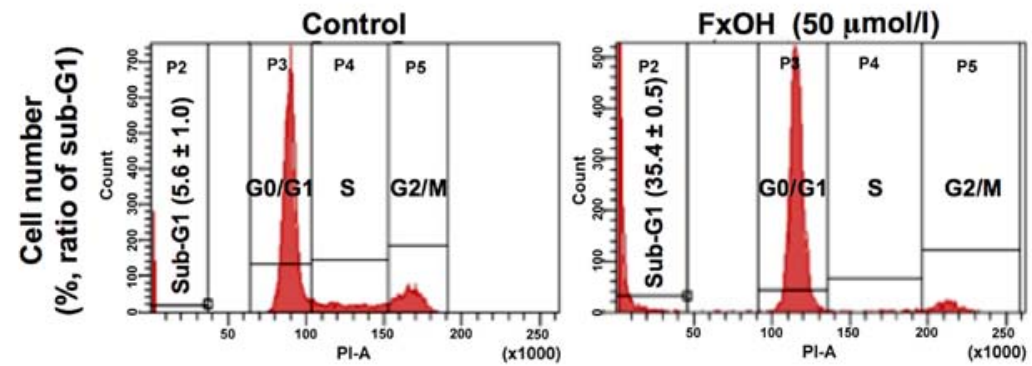

Figure 4. Antiproliferative effects of fucoxanthinol (FxOH) on colonospheres (Csps) derived from HT-29 and HCT116 cells. Csps formed with stem cell medium (SCM) for 2 days were treated with 10-50 $\mu \mathrm{M}$ FxOH for an additional $24 \mathrm{~h}$ under SCM. (A) Images of Csps derived from HT-29 and HCT116 cells treated with FxOH for 1 day by phase-contrast microscopy. Scale bar, $100 \mu \mathrm{m}$. (B) The cell viability of Csps derived from HT-29 and HCT116 cells was determined using a cell count assay with a trypan blue exclusion method. Values are the mean $\pm \mathrm{SE}(\mathrm{n}=3)$. ${ }^{*} \mathrm{P}<0.05$ (one-way ANOVA with post hoc Tukey-Kramer test). (C) The HT-29 Csps were treated with $50 \mu \mathrm{M} \mathrm{FxOH}$ or DMSO alone (control) for 1 day. Apoptosis was assessed by FACSaria-III analysis of propidium iodide (PI)-stained nuclei (sub-G1). Values are the mean $\pm \mathrm{SE}(\mathrm{n}=3)$.

signaling, the phosphorylation levels of C-Raf decreased in a time-dependent manner. The phosphorylation levels of MEK were reduced at $24 \mathrm{~h}$. The phosphorylation levels of ERK were downregulated only in HT-29 Csps. However, phosphorylation levels of p90RSK did not changed during the experiment. Regarding Stat signaling, phosphorylation levels of Stat3, Stat 5 and Stat6 were reduced clearly at $24 \mathrm{~h}$. We also observed reduced pro-caspase- 3 at $24 \mathrm{~h}$ and cleaved p17/p19 (active forms of caspase-3) at $24 \mathrm{~h}$ and reduced p53 levels. As shown in the figure, phosphorylated MSK1, Stat1 and Stat 2 were not detected in this experiment.

Time-dependent metabolite levels in colonospheres after FxOH treatment. To investigate $\mathrm{FxOH}$-induced metabolite alterations in Csps, levels of the two metabolites were evaluated in HT-29 and HCT116 Csps treated with $50 \mu \mathrm{M}$ FxOH for 4, 8 and 24 h. FxOH significantly increased glycine levels from 0 until $8 \mathrm{~h}$ and decreased glycine levels from 8 until $24 \mathrm{~h}$ in HT-29 Csps. Succinic acid levels in both Csps treated with FxOH were drastically decreased at 8 or $24 \mathrm{~h}$ compared with levels in each Csps at $0 \mathrm{~h}$ (Fig. 8).

\section{Discussion}

The results of the present study suggest that fucoxanthinol (FxOH) suppressed EMT. Conversely, glycine and succinic acid were found to be prognostic indicators of physiological changes in Csps treated with FxOH. This is the first study demonstrating EMT inhibition by $\mathrm{FxOH}$ treatment accompanied by detectable metabolite alterations. In addition, $\mathrm{FxOH}$ 

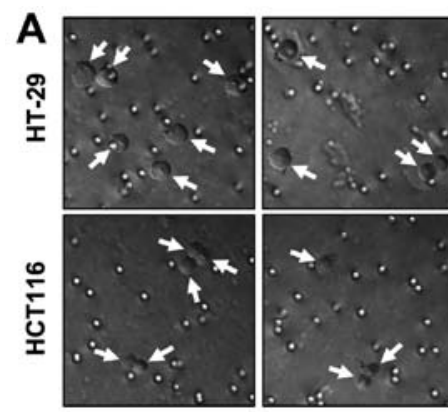

20

$\mathrm{FxOH}(\mu \mathrm{mol} / \mathrm{l})$

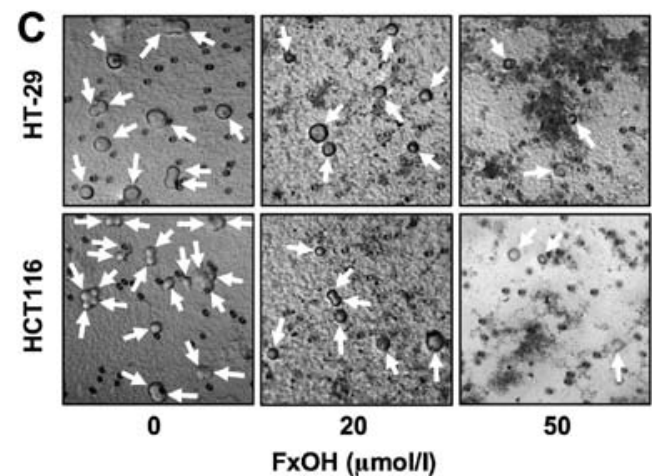

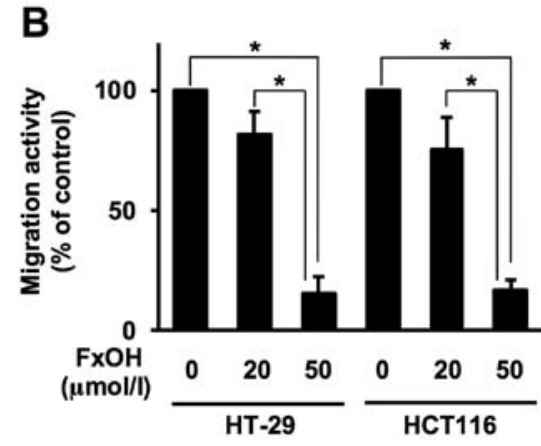

D

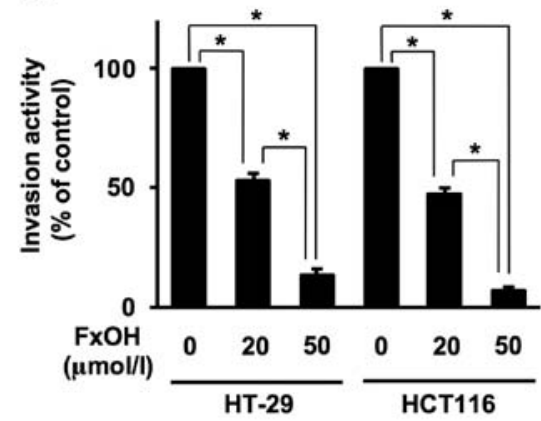

Figure 5. Suppressive effects of fucoxanthinol (FxOH) on the migration and invasion of colonospheres (Csps) derived from HT-29 and HCT116 cells. Csps were allowed to form with stem cell medium (SCM) for 2 days. Dispersed cells were treated with 20 and $50 \mu \mathrm{M}$ FxOH under SCM and applied to Transwell and invasion chambers. The migration and invasion capacities of these cells were measured after incubation for 6 and 24 h, respectively. (A and C) Images of migrated and invaded cells (white arrows). (B and D) Migrated and invaded cells were formalin-fixed and stained with Giemsa solution. Migration and invasion activities were evaluated by performing a cell count assay. Values are the mean \pm SE $(n=4)$. * $<<0.05$ (one-way ANOVA with post hoc Tukey-Kramer test).

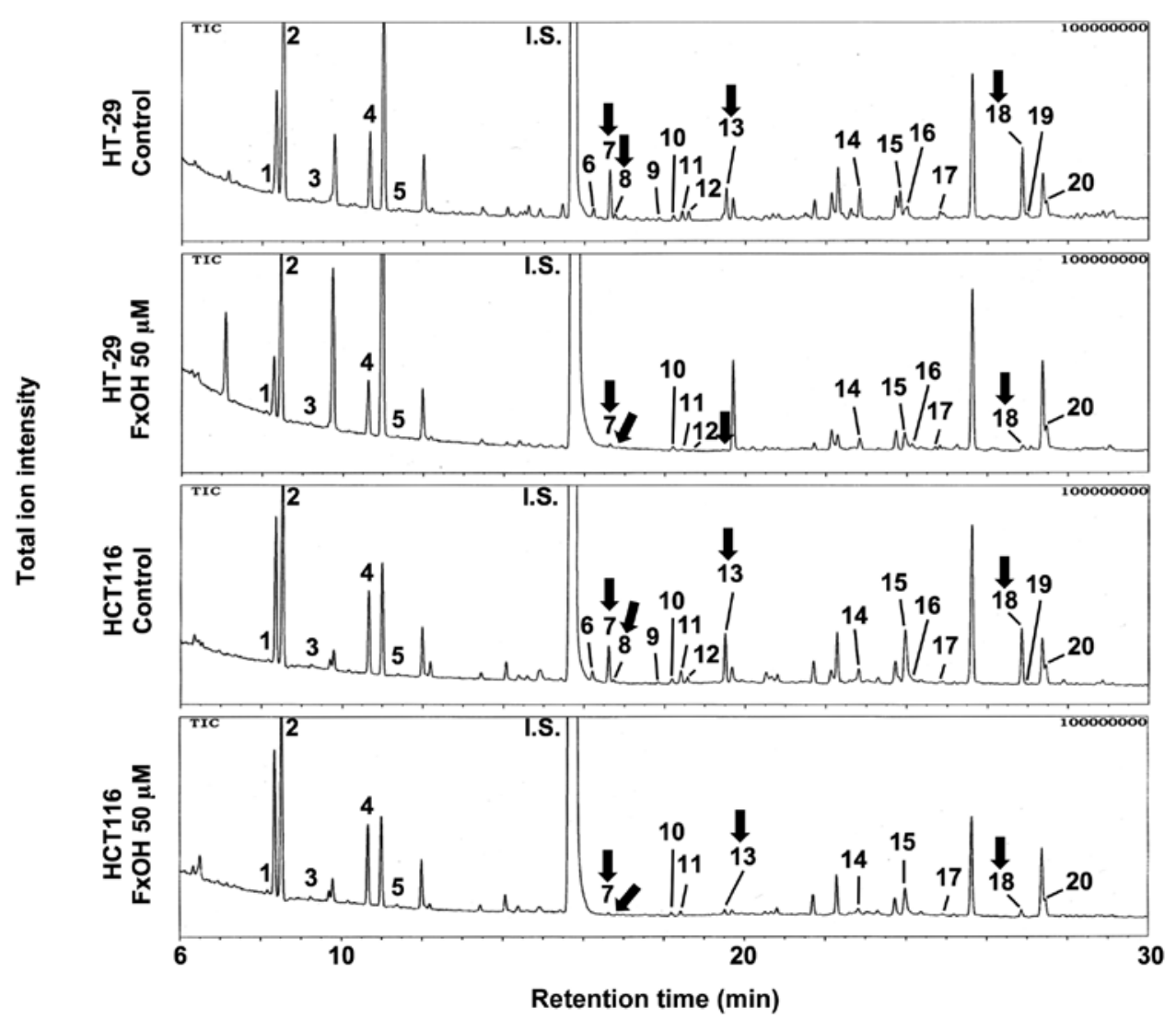

Figure 6. GC-MS total ion chromatograms of metabolites in colonospheres (Csps) derived from HT-29 and HCT116 cells following fucoxanthinol (FxOH) treatment. Csps of HT-29 and HCT116 cells were treated with FxOH for 24 h and collected, and their metabolites were analyzed by GC-MS. Peak nos. 7, 8,13 and 18 indicate glycine, threonine, glutamic acid and succinic acid, respectively (black arrows). Information on the cellular metabolites corresponding to each peak number is documented in Table II. GC-MS conditions are provided in Materials and methods. 
Table II. Metabolite profiles of colonospheres from the HT-29 and HCT116 cells following FxOH treatment at $24 \mathrm{~h}$.

\begin{tabular}{|c|c|c|c|c|c|}
\hline \multirow[b]{3}{*}{ Peak no. ${ }^{a}$} & \multirow[b]{3}{*}{ Group - compound } & \multicolumn{4}{|c|}{$\mathrm{pmol}$ metabolite $/ \mu \mathrm{g}$ total protein content } \\
\hline & & \multicolumn{2}{|c|}{ HT-29 cells } & \multicolumn{2}{|c|}{ HCT116 cells } \\
\hline & & Control & $\mathrm{FxOH}$ & Control & $\mathrm{FxOH}$ \\
\hline & Amino acid & & & & \\
\hline 3 & Valine & $2.5 \pm 1.5$ & $1.0 \pm 1.0$ & $1.8 \pm 1.8$ & $1.5 \pm 0.7$ \\
\hline 5 & Leucine & $3.7 \pm 2.1$ & $0.9 \pm 0.9$ & $1.6 \pm 0.5$ & $0.7 \pm 0.7$ \\
\hline 6 & Proline & $8.6 \pm 4.4$ & $21.0 \pm 11.0$ & $4.3 \pm 4.3$ & ND \\
\hline 7 & Glycine & $35.9 \pm 0.7$ & $14.1 \pm 6.4^{\mathrm{b}}$ & $29.6 \pm 5.7$ & $6.5 \pm 2.5^{\mathrm{b}}$ \\
\hline 11 & Aranine & $2.7 \pm 2.7$ & $0.3 \pm 0.3$ & $4.5 \pm 4.5$ & $1.9 \pm 1.0$ \\
\hline 12 & Serine & $3.8 \pm 2.1$ & $2.4 \pm 1.5$ & $5.0 \pm 1.8$ & $0.6 \pm 0.6$ \\
\hline 13 & Threonine & $15.3 \pm 5.1$ & $6.7 \pm 3.8$ & $22.7 \pm 3.9$ & $3.3 \pm 0.8^{\mathrm{b}}$ \\
\hline 15 & Aspartic acid & $10.1 \pm 4.8$ & $2.2 \pm 1.1$ & $5.9 \pm 3.4$ & $0.8 \pm 0.8$ \\
\hline 18 & Glutamic acid & $29.1 \pm 8.2$ & $11.3 \pm 4.9$ & $31.0 \pm 2.1$ & $7.8 \pm 3.0^{\mathrm{b}}$ \\
\hline \multirow[t]{2}{*}{19} & Phenylalanine & $2.6 \pm 0.3$ & $0.7 \pm 0.7$ & $0.8 \pm 0.8$ & $0.9 \pm 0.9$ \\
\hline & Dicarboxylic acid (TCA cycle) & & & & \\
\hline 8 & Succinic acid & $6.7 \pm 1.4$ & $0.6 \pm 0.6^{b}$ & $1.6 \pm 0.3$ & $\mathrm{ND}^{\mathrm{b}}$ \\
\hline 9 & Fumaric acid & $1.5 \pm 1.2$ & $0.6 \pm 0.6$ & $0.9 \pm 0.9$ & $0.3 \pm 0.3$ \\
\hline \multirow[t]{2}{*}{14} & Malic acid & $13.9 \pm 4.0$ & $4.2 \pm 2.1$ & $6.2 \pm 2.3$ & $2.1 \pm 1.4$ \\
\hline & Carboxylic acid & & & & \\
\hline 1 & Pyruvic acid & $1.0 \pm 1.0$ & $1.1 \pm 1.1$ & $2.7 \pm 0.5$ & $2.4 \pm 0.3$ \\
\hline 2 & Propionic acid & $188.5 \pm 42.8$ & $110.2 \pm 31.5$ & $121.2 \pm 32.0$ & $91.0 \pm 27.9$ \\
\hline 4 & Butyric acid & $44.9 \pm 11.6$ & $31.2 \pm 3.9$ & $42.6 \pm 14.5$ & $21.4 \pm 13.2$ \\
\hline 10 & Pelargonic acid & $3.0 \pm 1.7$ & $3.1 \pm 0.2$ & $3.6 \pm 1.2$ & $1.6 \pm 1.0$ \\
\hline 16 & $\gamma$-aminobutyric acid & $16.0 \pm 2.7$ & $5.4 \pm 2.8$ & $30.7 \pm 18.1$ & $8.2 \pm 6.9$ \\
\hline 17 & 2,3,4-Trihydroxybutyric acid & $2.7 \pm 0.8$ & $1.7 \pm 1.0$ & ND & $0.3 \pm 0.3$ \\
\hline 20 & Lauric acid & $9.7 \pm 2.7$ & $10.1 \pm 3.0$ & $15.3 \pm 1.6$ & $14.7 \pm 4.3$ \\
\hline
\end{tabular}

All data are expressed as the mean $\pm \mathrm{SE}\left(\mathrm{n}=3\right.$ ). ${ }^{\mathrm{a}}$ The number of peaks shown in Fig. $6 .{ }^{\mathrm{b}} \mathrm{P}<0.05$ (one-way ANOVA followed by post hoc Tuker-Kramer test vs. parental cells of each cell type). ND, a metabolite was not detected over signal/noise ratio (3:1) by GC-MS.

induced apoptosis by inhibiting integrin, MAPK and Stat signaling activations. Moreover, the decrease in p53 expression and activation of caspase- 3 were suggested to be involved in FxOH-induced apoptosis in HT-29 and HCT116 Csps.

We first confirmed the existence of CCSC surface protein markers and EMT phenotype protein markers in HT-29 and HCT116 Csps (Fig. 2). The enhancement of CD44v, EpCAM, LGR5 and vimentin, an EMT marker, suggested that both Csps possessed CCSC and EMT properties. In general, the suppression of E-cadherin expression in cancer cells indicated their transformation into the EMT phenotype. Thus, the upregulation of E-cadherin and vimentin observed in this study represented a lack of consistency. Indeed, other researchers observed decreased E-cadherin and increased vimentin in Csps formed from HT-29 and HCT116 PCs (30). Although we have no idea why E-cadherin was increased in the Csps compared with PCs in this experiment, we used these Csps as a near-Csp model. Regarding N-cadherin, it is generally acknowledged that this marker as well as vimentin may be elevated upon transformation into the EMT phenotype.

We also found that incubation with SCM for both HT-29 and HCT116 Csps resulted in metabolic reprogramming during the PC to Csp steps, in which glycine, serine, threonine, glutamic acid and succinic acid levels were significantly elevated. In addition, these metabolites showed a similar increase in Csps formed from HT-29 PCs, although without significance (Fig. 3 and Table I). It is speculated that the activation of cytosol glycolysis and serine metabolism and the promotion of the mitochondrial GSH/GSSG redox system and TCA cycle are essential metabolic pathways in Csps derived from HT-29 and HCT116 PCs. Positive aerobic glycolysis and subsequent metabolic reprogramming in cancer cells are collectively known as the Warburg effect (31). Various researchers have demonstrated the impact of the Warburg effect on the metabolite profiles of CSCs or CSC-like spheroids reconstructed from original breast, colorectal, hepatic and ovarian cancer PCs (32-36). Among the amino acids, aspartate, serine, glutamic acid and glutamine are assumed to be particularly good targets for cancer therapeutics in CSCs. Furthermore, several pathways, such as amino acid metabolism, the redox system, the TCA cycle and fatty acid biosynthesis, are also targets of CSCs. However, the precise mechanisms and physiological significance underlying the metabolite contents of CSCs remain unclear. 


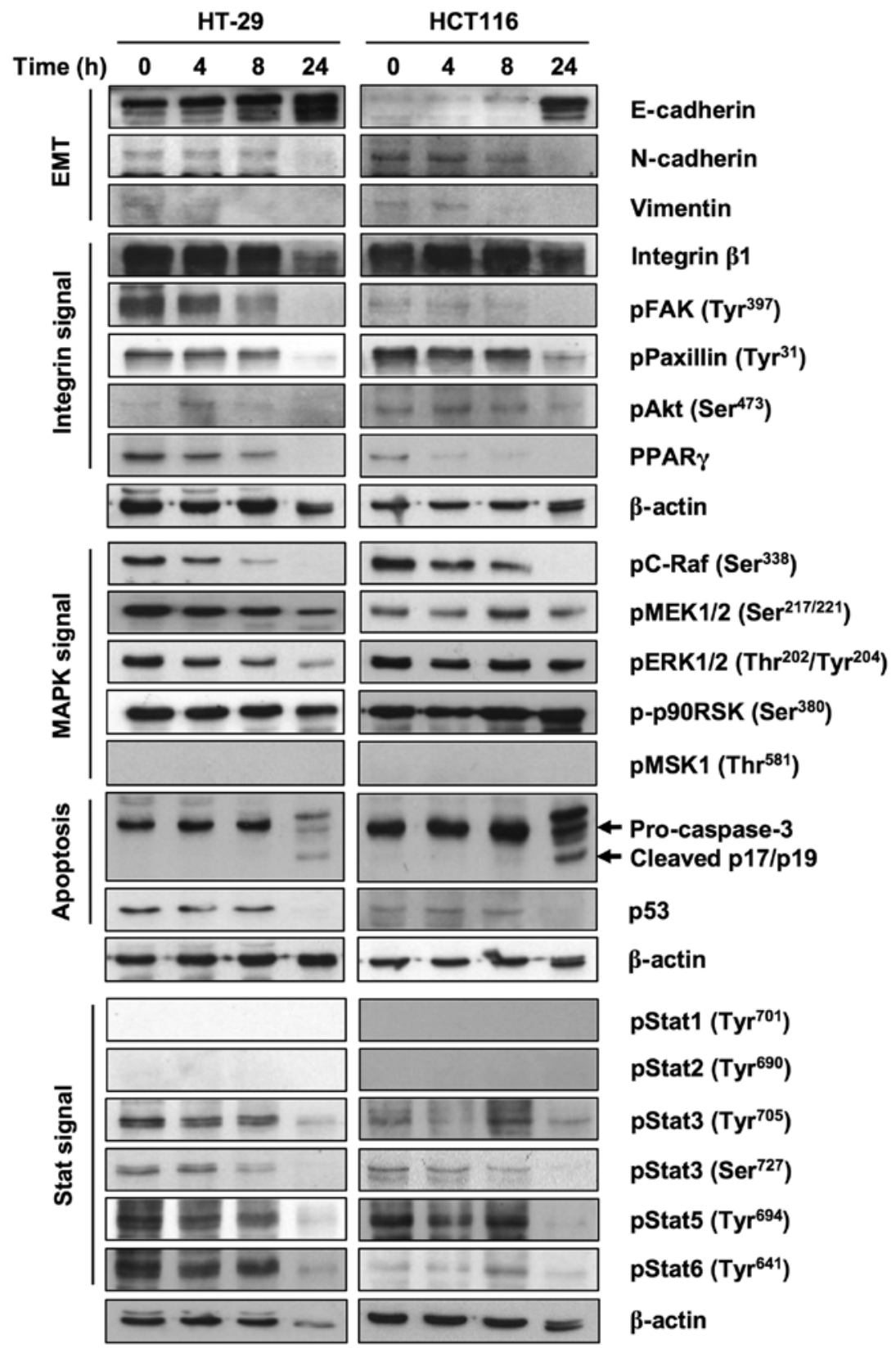

Figure 7. Western blot analysis of colonospheres (Csps) derived from HT-29 and HCT116 cells treated with fucoxanthinol (FxOH). Csps were allowed to form from HT-29 and HCT116 cells in stem cell medium (SCM) for 2 days were then treated with $50 \mu \mathrm{M}$ FxOH for an additional 4, 8 and $24 \mathrm{~h}$ under SCM. The Csps were collected, and their protein levels were determined by western blotting. $\beta$-actin is showed as a loading control per protein expression set for each different membrane as follows: membrane 1, EMT and integrin signal; membrane 2, MAPK and apoptosis; membrane 3, Stat signal.

Properties such as gene expression, morphology and chemoresistance differ between HT-29 and HCT116 cells. For example, HT-29 is p53-mutant and HCT116 is p53-wild-type (37). Although HCT116 cells possess a phenotype that more closely resembles EMT compared with that of HT-29 cells, both cell types demonstrated similar capacity in terms of invasion, sphere formation and tumorigenicity $(30,38)$. HCT116 cells are more sensitive to 5-fluorouracil treatment than HT-29 cells (39). In the present study, FxOH inhibited sphere formation, migration and invasion to the same degree in both Csp types and induced apoptosis through the same molecular regulations with similar temporal expression patterns (Figs. 4, 5 and 7). We previously reported that $\mathrm{FxOH}$ induced apoptosis along with the downregulation of pAkt
$\left(\mathrm{Ser}^{473}\right)$, peroxisome proliferator-activated receptor (PPAR) $\beta / \delta$ and PPAR $\gamma$ in HT-29 Csps (26). In the present study, we further showed that $\mathrm{FxOH}$ treatment began to suppress PPAR $\gamma$ and inhibit pC-Raf $\left(\operatorname{Ser}^{338}\right)$ starting at $4 \mathrm{~h}$, and decreased amounts of vimentin or increased E-cadherin levels were observed at $8 \mathrm{~h}$, followed by caspase- 3 activation and p53 depression at $24 \mathrm{~h}$ in both Csps. A highly polar xanthophyll, astaxanthin, as well as FxOH both inhibit EMT accompanied by the attenuation of reactive oxygen species production, inflammatory cytokine production and NF- $\kappa \mathrm{B}$ activation in rat peritoneal mesothelial cells (40). The apocarotenoids crocetin and crocin promote EMT attenuation by inhibiting $\mathrm{N}$-cadherin and $\beta$-catenin expression and increasing E-cadherin expression in aggressive prostate cancer PC3 and 22rvl cells (41). 


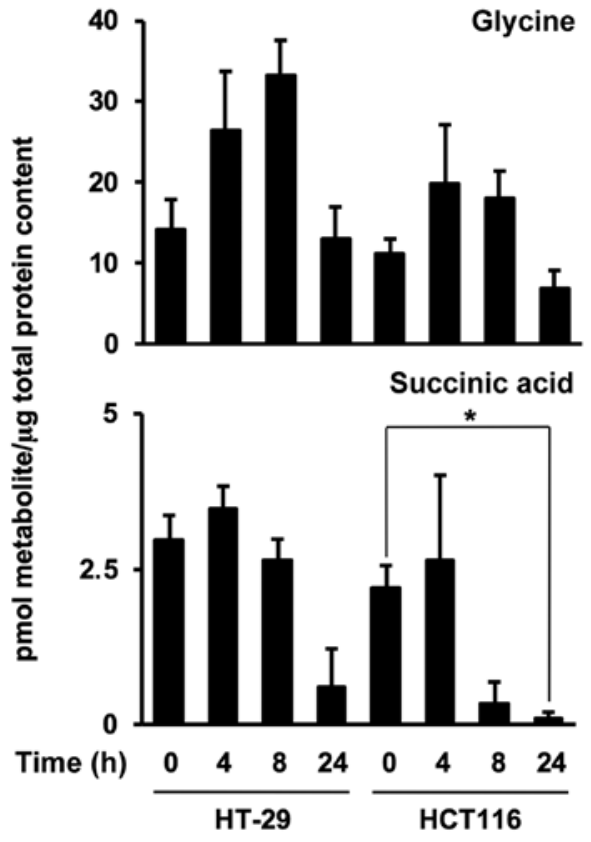

Figure 8. Time-dependent changes in metabolites followed by fucoxanthinol (FxOH) treatment of colonospheres (Csps) derived from HCT116 cells. Csps were allowed to form in stem cell medium (SCM) for 2 days and were then treated with $50 \mu \mathrm{M} \mathrm{FxOH}$ for an additional 4,8 and $24 \mathrm{~h}$ under SCM. The Csps were collected, and two metabolites were analyzed by GC-MS. GC-MS conditions are provided in Materials and methods. Values are the mean $\pm \mathrm{SE}$ $(\mathrm{n}=3)$. A significant difference $\left({ }^{*} \mathrm{P}<0.05\right)$ only between 0 and $24 \mathrm{~h}$ in succinic acid in HCT116 Csps was obtained for multiple comparisons by using oneway ANOVA followed by post hoc Tukey-Kramer test.

In addition to regulating proteins, the metabolite changes in Csps treated with FxOH were very similar between each cell type (Figs. 6 and 8, and Table II). FxOH treatment markedly decreased glycine and succinic acid in both Csps at 8 or $24 \mathrm{~h}$. Therefore, FxOH may attenuate the mitochondrial GSH/GSSG redox system and TCA cycle in Csps. Previously, Fx was shown to rapidly elicit the mitochondrial membrane potential in human promyelocytic leukemia HL-60 and HP100-1 cells (16). Our findings indicate that $\mathrm{FxOH}$ treatment may accompany the mitochondrial disruption of spheroids, regardless of the different phenotypes of cancer cells. Little is known about changes to anti-metabolism capacity by carotenoids in CSCs or CSC-like spheroids. A randomized, double-blind, placebocontrolled study, the Alpha-Tocopherol, Beta-Carotene Cancer Prevention (ATBC) Study, demonstrated that $\beta$-carotene significantly increased 17 metabolites in the sera of male smokers (42). In a diethylnitrosamine (DEN)-induced mouse hepatic tumor model, acyclic retinoid (0.06\%) administration resulted in significant changes in 88 metabolites in liver tumor tissue compared with mice that did not receive DEN treatment (43). In contrast, a colorimetric lipid, curcumin, induced apoptosis accompanied by glutamine reduction in CD44-positive CSC-like cells derived from HT-29 cells (44). Some anticancer drugs such as 5-fluorouracil and gemcitabine alter cellular metabolism pathways (45). In the present study, we revealed that $\mathrm{FxOH}$ exerts anti-metabolism activity in cancer cells similar to that observed for other carotenoid or carotenoid-derived compounds and anticancer drugs.

In summary, FxOH attenuated EMT, inhibited the activation of integrin, MAPK, and Stat signaling and altered metabolite profiles in CSC-like cells of Csps derived from human CRC HT-29 and HCT116 cells. Glycine and succinic acid were suggested to be metabolite markers of EMT suppression induction in Csps. Further studies may reveal that these two metabolites are helpful in understanding the cellular conditions of CCSCs in human or animal colorectal mucosal tissue following $\mathrm{Fx}$ or $\mathrm{FxOH}$ administration.

\section{Acknowledgements}

Not applicable.

\section{Funding}

The present study was supported in part by a grant from Japan Society for the Promotion of Science KAKENHI (no. 16K07880).

\section{Availability of data and materials}

The datasets used during the present study are available from the corresponding author upon reasonable request.

\section{Authors' contributions}

MT and MM conceived and designed the study. MT, MM and SK performed the experiments. MT and MM wrote the paper. TE, $\mathrm{HM}, \mathrm{JH}, \mathrm{KO}$ and $\mathrm{KM}$ performed interepretation of data, reviewed and edited the manuscript. All authors read and approved the manuscript and agree to be accountable for all aspects of the research in ensuring that the accuracy or integrity of any part of the work are appropriately investigated and resolved.

\section{Ethics approval and consent to participate}

Not applicable.

\section{Consent for publication}

Not applicable.

\section{Competing interests}

The authors state that they have no competing interests.

\section{References}

1. Terasaki M, Hirose A, Narayan B, Baba Y, Kawagoe C, Yasui H, Saga N, Hosokawa M and Miyashita K: Evaluation of recoverable functional lipid components of several brown seaweeds (phaeophyta) from Japan with special reference to fucoxanthin and fucosterol contents. J Phycol 45: 974-980, 2009.

2. Terasaki M, Narayan B, Kamogawa H, Nomura M, Stephen NM, Kawagoe C, Hosokawa M and Miyashita K: Carotenoid profile of edible Japanese seaweeds: An improved HPLC method for separation of major carotenoids. J Aquat Food Prod Technol 21: 468-479, 2012.

3. Beppu F, Niwano Y, Tsukui T, Hosokawa M and Miyashita K: Single and repeated oral dose toxicity study of fucoxanthin (FX), a marine carotenoid, in mice. J Toxicol Sci 34: 501-510, 2009.

4. Iio K, Okada Y and Ishikura M: Single and 13-week oral toxicity study of fucoxanthin oil from microalgae in rats. Shokuhin Eiseigaku Zasshi 52: 183-189, 2011 (In Japanese).

5. Okuzumi J, Takahashi T, Yamane T, Kitao Y, Inagake M, Ohya K, Nishino $\mathrm{H}$ and Tanaka Y: Inhibitory effects of fucoxanthin, a natural carotenoid, on $N$-ethyl- $N$ '-nitro- $N$-nitrosoguanidine-induced mouse duodenal carcinogenesis. Cancer Lett 68: 159-168, 1993. 
6. Kim JM, ArakiS,Kim DJ,Park CB, Takasuka N, Baba-Toriyama H, Ota T, Nir Z, Khachik F, Shimidzu N, et al: Chemopreventive effects of carotenoids and curcumins on mouse colon carcinogenesis after 1,2-dimethylhydrazine initiation. Carcinogenesis 19: 81-85, 1998.

7. Nishino H: Cancer prevention by carotenoids. Mutat Res 402: 159-163, 1998.

8. Shiratori K, Ohgami K, Ilieva I, Jin XH, Koyama Y, Miyashita K, Yoshida K, Kase S and Ohno S: Effects of fucoxanthin on lipopolysaccharide-induced inflammation in vitro and in vivo. Exp Eye Res 81: 422-428, 2005.

9. Nishikawa S, Hosokawa M and Miyashita K: Fucoxanthin promotes translocation and induction of glucose transporter 4 in skeletal muscles of diabetic/obese KK- $A^{y}$ mice. Phytomedicine 19 : 389-394, 2012.

10. Maeda H,Hosokawa M, Sashima T, Funayama K and Miyashita K Fucoxanthin from edible seaweed, Undaria pinnatifida, shows antiobesity effect through UCP1 expression in white adipose tissues. Biochem Biophys Res Commun 332: 392-397, 2005.

11. Hitoe $S$ and Shimoda H: Seaweed fucoxanthin supplementation improves obesity parameters in mildly obese Japanese subjects. Funct Food Health Dis 7: 246-262, 2017.

12. Hosokawa M, Kudo M, Maeda H, Kohno H, Tanaka $\mathrm{T}$ and Miyashita K: Fucoxanthin induces apoptosis and enhances the antiproliferative effect of the PPARgamma ligand, troglitazone, on colon cancer cells. Biochim Biophys Acta 1675: 113-119, 2004.

13. Das SK, Hashimoto T and Kanazawa K: Growth inhibition of human hepatic carcinoma HepG2 cells by fucoxanthin is associated with down-regulation of cyclin D. Biochim Biophys Acta 1780: 743-749, 2008.

14. Murakami C, Takemura M, Sugiyama Y, Kamisuki S, Asahara H, Kawasaki M, Ishidoh T, Linn S, Yoshida S, Sugawara F, et al: Vitamin A-related compounds, all-trans retinal and retinoic acids, selectively inhibit activities of mammalian replicative DNA polymerases. Biochim Biophys Acta 1574: 85-92, 2002.

15. Okuzumi J, Nishino H, Murakoshi M, Iwashima A, Tanaka Y, Yamane T, Fujita Y and Takahashi T: Inhibitory effects of fucoxanthin, a natural carotenoid, on $\mathrm{N}-m y c$ expression and cell cycle progression in human malignant tumor cells. Cancer Lett 55: 75-81, 1990.

16. Kotake-Nara E, Terasaki M and Nagao A: Characterization of apoptosis induced by fucoxanthin in human promyelocytic leukemia cells. Biosci Biotechnol Biochem 69: 224-227, 2005.

17. Asai A, Sugawara T, Ono H and Nagao A: Biotransformation of fucoxanthinol into amarouciaxanthin A in mice and HepG2 cells: Formation and cytotoxicity of fucoxanthin metabolites. Drug Metab Dispos 32: 205-211, 2004.

18. Asai A, Yonekura L and Nagao A: Low bioavailability of dietary epoxyxanthophylls in humans. Br J Nutr 100: 273-277, 2008.

19. Hashimoto T, Ozaki Y, Mizuno M, Yoshida M, Nishitani Y, Azuma T, Komoto A, Maoka T, Tanino Y and Kanazawa K: Pharmacokinetics of fucoxanthinol in human plasma after the ora administration of kombu extract. Br J Nutr 107: 1566-1569, 2012.

20. Takahashi K, Hosokawa M, Kasajima H, Hatanaka K, Kudo K, Shimoyama N and Miyashita K: Anticancer effects of fucoxanthin and fucoxanthinol on colorectal cancer cell lines and colorectal cancer tissues. Oncol Lett 10: 1463-1467, 2015.

21. Ferlay J, Soerjomataram I, Dikshit R, Eser S, Mathers C, Rebelo M, Parkin DM, Forman D and Bray F: Cancer incidence and mortality worldwide: Sources, methods and major patterns in GLOBOCAN 2012. Int J Cancer 136: E359-E386, 2015.

22. Dalerba P, Dylla SJ, Park IK, Liu R, Wang X, Cho RW, Hoey T, Gurney A, Huang EH, Simeone DM, et al: Phenotypic characterization of human colorectal cancer stem cells. Proc Natl Acad Sci USA 104: 10158-10163, 2007.

23. Vermeulen L, Todaro M, de Sousa Mello F, Sprick MR, Kemper K, Perez Alea M, Richel DJ, Stassi G and Medema JP: Single-cell cloning of colon cancer stem cells reveals a multilineage differentiation capacity. Proc Natl Acad Sci USA 105: 13427-13432, 2008.

24. Findlay VJ, Wang C, Watson DK and Camp ER: Epithelial-tomesenchymal transition and the cancer stem cell phenotype: Insights from cancer biology with therapeutic implications for colorectal cancer. Cancer Gene Ther 21: 181-187, 2014.

25. Kanwar SS, Yu Y, Nautiyal J, Patel BB and Majumdar AP: The Wnt/beta-catenin pathway regulates growth and maintenance of colonospheres. Mol Cancer 9: 212-225, 2010.
26. Terasaki M, Maeda H, Miyashita K, Tanaka T, Miyamoto S and Mutoh M: A marine bio-functional lipid, fucoxanthinol, attenuates human colorectal cancer stem-like cell tumorigenicity and sphere formation. J Clin Biochem Nutr 61: 25-32, 2017.

27. Yoshida M, Hatano N, Nishiumi S, Irino Y, Izumi Y, Takenawa T and Azuma T: Diagnosis of gastroenterological diseases by metabolome analysis using gas chromatography-mass spectrometry. J Gastroenterol 47: 9-20, 2012.

28. Dazard JE, Sandlers Y, Doerner SK, Berger NA and Brunengraber $\mathrm{H}$ : Metabolomics of $\mathrm{Apc}^{\mathrm{Min} / \mathrm{+}}$ mice genetically susceptible to intestinal cancer. BMC Syst Biol 8: 72, 2014.

29. Yoshie T, Nishiumi S, Izumi Y, Sakai A, Inoue J, Azuma T and Yoshida M: Regulation of the metabolite profile by an APC gene mutation in colorectal cancer. Cancer Sci 103: 1010-1021, 2012.

30. Han XY, Wei B, Fang JF, Zhang S, Zhang FC, Zhang HB, Lan TY, Lu HQ and Wei HB: Epithelial-mesenchymal transition associates with maintenance of stemness in spheroid-derived stem-like colon cancer cells. PLoS One 8: e73341, 2013.

31. Warburg O: On the origin of cancer cells. Science 123: 309-314, 1956.

32. Sato M, Kawana K, Adachi K, Fujimoto A, Yoshida M, Nakamura H, Nishida H, Inoue T, Taguchi A, Takahashi J, et al: Spheroid cancer stem cells display reprogrammed metabolism and obtain energy by actively running the tricarboxylic acid (TCA) cycle. Oncotarget 7: 33297-33305, 2016.

33. Vermeersch KA, Wang L, Mezencev R, McDonald JF and Styczynski MP: OVCAR-3 spheroid-derived cells display distinct metabolic profiles. PLoS One 10: e0118262, 2015.

34. Penkert J, Ripperger T, Schieck M, Schlegelberger B, Steinemann D and Illig T: On metabolic reprogramming and tumor biology: A comprehensive survey of metabolism in breast cancer. Oncotarget 7: 67626-67649, 2016.

35. Lin SH, Liu T, Ming X, Tang Z, Fu L, Schmitt-Kopplin P, Kanawati B, Guan XY and Cai Z: Regulatory role of hexosamine biosynthetic pathway on hepatic cancer stem cell marker CD133 under low glucose conditions. Sci Rep 6: 21184, 2016.

36. Chen KY, Liu X, Bu P, Lin CS, Rakhilin N, Locasale JW and Shen X: A metabolic signature of colon cancer initiating cells. Conf Proc IEEE Eng Med Biol Soc 2014: 4759-4762, 2014.

37. Küntzer J, Eggle D, Lenhof HP, Burtscher H and Klostermann S: The roche cancer genome database (RCGDB). Hum Mutat 31: 407-413, 2010.

38. Matsuda Y, Miura K, Yamane J, Shima H, Fujibuchi W, Ishida K, Fujishima F, Ohnuma S, Sasaki H, Nagao M, et al: SERPINI1 regulates epithelial-mesenchymal transition in an orthotopic implantation model of colorectal cancer. Cancer Sci 107: 619-628, 2016.

39. Russo P, Malacarne D, Falugi C, Trombino S and O'Connor PM: RPR-115135, a farnesyltransferase inhibitor, increases 5-FUcytotoxicity in ten human colon cancer cell lines: Role of p53. Int J Cancer 100: 266-275, 2002.

40. Hara K, Hamada C, Wakabayashi K, Kanda R, Kaneko K, Horikoshi S, Tomino Y and Suzuki Y: Scavenging of reactive oxygen species by astaxanthin inhibits epithelial-mesenchymal transition in high glucose-stimulated mesothelial cells. PLoS One 12: e0184332, 2017.

41. Festuccia C, Mancini A, Gravina GL, Scarsella L, Llorens S, Alonso GL, Tatone C, Di Cesare E, Jannini EA, Lenzi A, et al: Antitumor effects of saffron-derived carotenoids in prostate cancer cell models. BioMed Res Int 2014: 135048, 2014.

42. Mondul AM, Sampson JN, Moore SC, Weinstein SJ, Evans AM, Karoly ED, Virtamo J and Albanes D: Metabolomic profile of response to supplementation with $\beta$-carotene in the AlphaTocopherol, Beta-Carotene Cancer Prevention Study. Am J Clin Nutr 98: 488-493, 2013

43. Qin XY, Tatsukawa H, Hitomi K, Shirakami Y, Ishibashi N, Shimizu M, Moriwaki H and Kojima S: Metabolome analyses uncovered a novel inhibitory effect of acyclic retinoid on aberrant lipogenesis in a mouse diethylnitrosamine-induced hepatic tumorigenesis model. Cancer Prev Res 9: 205-214, 2016.

44. Huang YT, Lin YW, Chiu HM and Chiang BH: Curcumin induces apoptosis of colorectal cancer stem cells by coupling with CD44 marker. J Agric Food Chem 64: 2247-2253, 2016.

45. Amelio I, Cutruzzolá F, Antonov A, Agostini M and Melino G Serine and glycine metabolism in cancer. Trends Biochem Sci 39: 191-198, 2014. 